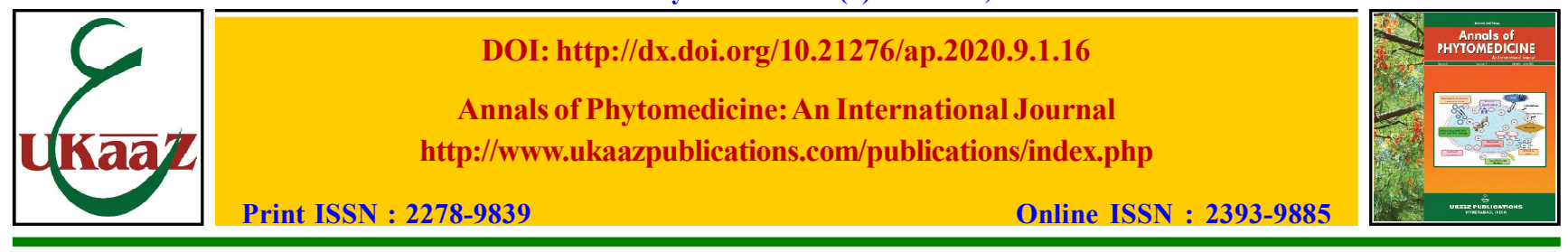

Original article: Open access

\title{
Processing of dragon fruit beverage by acoustic treatment
}

\author{
Minh Phuoc Nguyen* \\ Faculty of Biotechnology, Ho Chi Minh City Open University, Ho Chi Minh City, Vietnam
}

\section{Article Info}

Article history

Received 4 February 2020

Revised 29 March 2020

Accepted 5 April 2020

Published online 30 June 2020

Keywords

Dragon fruit

Beverage

Acoustic power

Extraction duration

Extraction temperature

\begin{abstract}
Dragon fruit is being prevailed globally because of its rich source of polyphenolic components and its antioxidant activities contributing to chemo-protective properties that is beneficial for human health. Our research penetrated on the utilization of acoustic treatment on dragon fruit mash to produce beverage. Different parameters of acoustic power are $(300,350,400,450,500 \mathrm{~W})$, treatment duration $(3.0,3.5,4.0,4.5,5.0 \mathrm{~min})$, treatment temperature $\left(35,45,55,65,75^{\circ} \mathrm{C}\right)$. Our results showed that acoustic power at $450 \mathrm{~W}$ in $4.5 \mathrm{~min}$ at $55^{\circ} \mathrm{C}$ had significant effect on the juice extraction recovery, vitamin $\mathrm{C}$, total phenolic content, total flavonoid content and organoleptic property of dragon fruit beverage. This finding gave a basic foundation for factual manufacturing in industrial scale. There is a possibility to enhance the added value of dragon fruit as well as contribute to the poverty reduction and hunger elimination for farmers in Vietnam.
\end{abstract}

\section{Introduction}

Dragon fruit (Hylocereus undatus (Haworth) Britton \& Rose) could be cultivated in the dry tropical climate (Ortizhernández and Carrillosalazar, 2012). It has red or white pulp with oval shape. It has a lot of tiny black seeds (Ortiz-Hernández et al., 2012). The fruit was often consumed fresh or processed form such as Jelly, Juice, Cordial, Jam, Ice cream, Sherbet, Yogurt, Candy, Pastry, Colorant, Wine, Nectar (Nurul et al., 2014; Barcelon et al., 2015; Islam et al., 2012; Panchal et al., 2018; Nguyen Phuoc Minh, 2014; Nguyen Phuoc Minh et al., 2019). It is rich in fiber, vitamins, calcium, phosphorus, magnesium, phytochemicals and antioxidants (Montadher et al., 2018; Hui et al., 2014; Sushmitha et al., 2018; Fernanda et al., 2014). Phytochemical constituents included triterpenoid, alkaloid, flavonoid and saponin (Sudha et al., 2017). These components contribute to various medicinal and pharmaceutical properties (Yogita et al., 2018).

Acoustic treatment can be considered as a cheap, simple, reliable, environmentally friendly, and innovative technology (Valero et al., 2007). The low frequency high power ultrasound has been popularly applied in food processing sector (Feng et al., 2008). In juice processing by ultrasound, there is a minimal effect on the ascorbic acid content, phenolic, anthocyanin in various materials such as strawberry, grape, citrus, olive, coconut, carrot, banana, etc. (Herrera et al., 2005; Rodrigues et al., 2007; Ma et al., 2009; Lieu et al., 2010; Zou et al., 2016; Lee et al., 2006). Ultrasonic

Corresponding author: Dr. Minh Phuoc Nguyen Faculty of Biotechnology, Ho Chi Minh City Open University, Ho Chi Minh City, Vietnam

E-mail: minh.np@ou.edu.vn

Tel.: +84-0947073637; +84-0984048200 treatment caused the collapse through cavitation in the surroundings of colloidal particles and then releases bioactive compounds from the cell wall (Chi and Ha, 2018). Purpose of our research focused on the utilization of acoustic treatment on dragon fruit mash to produce beverage.

\section{Materials and Methods}

\subsection{Material}

Dragon fruits were collected from Tien Giang province, Vietnam. After collecting, they must be conveyed to laboratory for experiments. They were washed under tap water to remove foreign matters and dripped excess water. Chemical substances such as Folin-Ciocalteu reagent, sodium carbonate anhydrous, gallic acid, sodium nitrite, aluminium chloride, catechin were all supplied from Labone Scientific Laboratory Vietnam. UV-spectrophotometer was used for measurement.

\subsection{Researching procedure}

Dragon fruit mash was treated with different acoustic power (300, $350,400,450,500 \mathrm{~W})$ at different extraction duration $(3.0,3.5$, $4.0,4.5,5.0 \mathrm{~min})$ and different extraction temperature $(35,45,55$, $\left.65,75^{\circ} \mathrm{C}\right)$. Ultrasonic bath operated at frequency of $37 \mathrm{kHz}$. The best acoustic power, extraction duration, extraction temperature were defined via extraction recovery (\%), vitamin C (mg/100 g), total phenolic content (TPC, mg GAE/100 g), total flavonoid content (TFC, mg CE/100 g) and organoleptic attribute (sensory score).

\subsection{Chemical analysis}

Extraction recovery (\%) was evaluated according to the formula described by Nguyen and Le (2012). Vitamin C (mg/100 g) was evaluated by 2,6 -dichlorophenolindophenol titration. Total phenolic 
content (TPC, mg GAE/100 g) was determined by the method of Li et al. (2008). Total flavonoid content (TFC, $\mathrm{mg} \mathrm{CE} / 100 \mathrm{~g}$ ) as determined by application of a method described by Ozsoy et al. (2008). Sensory score was estimated by a group of panelists using 9 point-Hedonic scale.

\subsection{Statistical analysis}

The experiments were run in triplicate with three different lots of samples. Statistical analysis was performed by the Statgraphics Centurion XVI.

\section{Results}

3.1 Effect of acoustic power to the juice extraction recovery, vitamin $\mathrm{C}$, total phenolic content, total flavonoid content, and organoleptic attribute of dragon fruit beverage

The highest significant juice extraction recovery (\%), vitamin $\mathrm{C}$ (mg/100 g), total phenolic content (TPC, mg GAE/100 g), total flavonoid content (TFC, $\mathrm{mg} \mathrm{CE} / 100 \mathrm{~g}$ ) and overall acceptance was noticed at acoustic power $450 \mathrm{~W}$, while at $300 \mathrm{~W}$ showed the lowest ones (Table 1).
3.2 Effect of extraction duration to the juice extraction recovery, vitamin $\mathrm{C}$, total phenolic content, total flavonoid content, and organoleptic attribute of dragon fruit beverage

Extraction duration is very important in decision of energy consumption and cost of the extraction assay. The highest significant juice extraction recovery (\%), vitamin C (mg/100 g), total phenolic content (TPC, mg GAE/100 g), total flavonoid content (TFC, mg $\mathrm{CE} / 100 \mathrm{~g}$ ) and overall acceptance were noticed at extraction duration $4.5 \mathrm{~min}$, while at $3.0 \mathrm{~min}$ showed the lowest ones (Table 2).

3.3 Effect of extraction temperature to the juice extraction recovery, vitamin $\mathrm{C}$, total phenolic content, total flavonoid content, and organoleptic attribute of dragon fruit beverage

In solid-liquid extraction, cavitation can cause surface erosion and particle breakdown (Vilkhu et al., 2008). The highest significant juice extraction recovery $(\%)$, vitamin $\mathrm{C}(\mathrm{mg} / 100 \mathrm{~g})$, total phenolic content (TPC, mg GAE/100 g), total flavonoid content (TFC, mg $\mathrm{CE} / 100 \mathrm{~g})$ and overall acceptance was noticed at $55^{\circ} \mathrm{C}$, while treatments at $75^{\circ} \mathrm{C}$ showed the lowest ones (Table 3).

Table 1: Effect of acoustic power (W) to juice extraction recovery (\%), vitamin C (mg/100 g), TPC (mg GAE/100 g), TFC (mg CE/100 g), organoleptic attribute of dragon fruit beverage

\begin{tabular}{|l|r|r|r|r|r|}
\hline Parameter & \multicolumn{5}{|c|}{ Acoustic power (W) } \\
\hline & 300 & \multicolumn{2}{|c|}{350} & 400 & \multicolumn{2}{c|}{450} & \\
\hline Juice recovery (\%) & $57.48 \pm 0.01^{\mathrm{c}}$ & $65.81 \pm 0.03^{\mathrm{b}}$ & $69.43 \pm 0.01^{\mathrm{ab}}$ & $73.95 \pm 0.00^{\mathrm{a}}$ & $74.05 \pm 0.01^{\mathrm{a}}$ \\
Vitamin C (mg/100 g) & $16.37 \pm 0.03^{\mathrm{c}}$ & $19.46 \pm 0.00^{\mathrm{b}}$ & $20.85 \pm 0.00^{\mathrm{ab}}$ & $21.46 \pm 0.01^{\mathrm{a}}$ & $21.53 \pm 0.00^{\mathrm{a}}$ \\
TPC (mg GAE/100 g) & $28.35 \pm 0.02^{\mathrm{c}}$ & $31.07 \pm 0.01^{\mathrm{b}}$ & $31.79 \pm 0.1^{\mathrm{ab}}$ & $32.28 \pm 0.00^{\mathrm{a}}$ & $32.31 \pm 0.00^{\mathrm{a}}$ \\
TFC (mg CE/100 g) & $9.54 \pm 0.00^{\mathrm{c}}$ & $11.22 \pm 0.02^{\mathrm{b}}$ & $11.79 \pm 0.02^{\mathrm{ab}}$ & $11.98 \pm 0.03^{\mathrm{a}}$ & $12.01 \pm 0.03^{\mathrm{a}}$ \\
Sensory score & $6.36 \pm 0.01^{\mathrm{c}}$ & $7.05 \pm 0.00^{\mathrm{b}}$ & $7.56 \pm 0.00^{\mathrm{ab}}$ & $7.87 \pm 0.02^{\mathrm{a}}$ & $7.90 \pm 0.01^{\mathrm{a}}$ \\
\hline
\end{tabular}

Note: The values were expressed as the mean of three repetitions; the same characters (denoted above), the difference between them was not significant $(\alpha=5 \%)$.

Table 2: Effect of extraction duration (min) to juice extraction recovery (\%), vitamin C (mg/100 g), TPC (mg GAE/100 g), TFC (mg CE/100 g), organoleptic attribute of dragon fruit beverage

\begin{tabular}{|l|c|c|c|r|c|}
\hline Parameter & \multicolumn{5}{|c|}{ Extraction duration (min) } \\
\hline & 3.0 & \multicolumn{2}{|c|}{3.5} & 4.0 & \multicolumn{3}{c|}{4.5} & 5.0 \\
\hline Juice recovery (\%) & $73.95 \pm 0.00^{\mathrm{c}}$ & $74.38 \pm 0.03^{\mathrm{bc}}$ & $74.95 \pm 0.01^{\mathrm{b}}$ & $75.41 \pm 0.02^{\mathrm{ab}}$ & $75.63 \pm 0.01^{\mathrm{a}}$ \\
Vitamin C (mg/100 g) & $21.46 \pm 0.01^{\mathrm{b}}$ & $21.89 \pm 0.00^{\mathrm{ab}}$ & $22.08 \pm 0.02^{\mathrm{ab}}$ & $22.75 \pm 0.03^{\mathrm{a}}$ & $22.80 \pm 0.03^{\mathrm{a}}$ \\
TPC (mg GAE/100 g) & $32.28 \pm 0.00^{\mathrm{b}}$ & $32.91 \pm 0.02^{\mathrm{ab}}$ & $33.41 \pm 0.00^{\mathrm{ab}}$ & $33.89 \pm 0.01^{\mathrm{a}}$ & $33.90 \pm 0.00^{\mathrm{a}}$ \\
TFC (mg CE/100 g) & $11.98 \pm 0.03^{\mathrm{b}}$ & $12.38 \pm 0.00^{\mathrm{ab}}$ & $12.65 \pm 0.00^{\mathrm{ab}}$ & $12.94 \pm 0.00^{\mathrm{a}}$ & $12.98 \pm 0.01^{\mathrm{a}}$ \\
Sensory score & $7.87 \pm 0.02^{\mathrm{c}}$ & $8.05 \pm 0.01^{\mathrm{bc}}$ & $8.16 \pm 0.01^{\mathrm{b}}$ & $8.43 \pm 0.02^{\mathrm{ab}}$ & $8.57 \pm 0.00^{\mathrm{a}}$ \\
\hline
\end{tabular}

Note: The values were expressed as the mean of three repetitions; the same characters (denoted above), the difference between them was not significant $(\alpha=5 \%)$.

Table 3: Effect of extraction temperature $\left({ }^{\circ} \mathrm{C}\right)$ to juice extraction recovery (\%), vitamin C (mg/100 g), TPC (mg GAE/100 g), TFC (mg CE/100 g), organoleptic attribute of dragon fruit beverage

\begin{tabular}{|c|c|c|c|c|c|}
\hline \multirow[t]{2}{*}{ Parameter } & \multicolumn{3}{|c|}{ Extraction temperature $\left({ }^{\circ} \mathrm{C}\right)$} & \multirow[b]{2}{*}{65} & \multirow[b]{2}{*}{75} \\
\hline & 35 & 45 & 55 & & \\
\hline Juice recovery $(\%)$ & $75.41 \pm 0.02^{\mathrm{b}}$ & $77.81 \pm 0.00^{\mathrm{ab}}$ & $79.48 \pm 0.02^{\mathrm{a}}$ & $89.51 \pm 0.01^{\mathrm{a}}$ & $89.56 \pm 0.03^{\mathrm{a}}$ \\
\hline Vitamin C (mg/100 g) & $22.75 \pm 0.03^{b}$ & $23.81 \pm 0.03^{\mathrm{ab}}$ & $24.39 \pm 0.00^{\mathrm{a}}$ & $21.53 \pm 0.02^{\mathrm{c}}$ & $19.28 \pm 0.00^{\mathrm{d}}$ \\
\hline TPC (mg GAE/100 g) & $33.89 \pm 0.01^{\mathrm{b}}$ & $35.06 \pm 0.02^{\mathrm{ab}}$ & $37.41 \pm 0.01^{\mathrm{a}}$ & $32.05 \pm 0.00^{\mathrm{c}}$ & $28.41 \pm 0.02^{\mathrm{d}}$ \\
\hline TFC (mg CE/100 g) & $12.94 \pm 0.00^{\mathrm{b}}$ & $13.48 \pm 0.00^{\mathrm{ab}}$ & $13.86 \pm 0.00^{\mathrm{a}}$ & $11.03 \pm 0.01^{\mathrm{c}}$ & $9.21 \pm 0.01^{\mathrm{d}}$ \\
\hline Sensory score & $8.43 \pm 0.02^{\mathrm{b}}$ & $8.67 \pm 0.01^{\mathrm{ab}}$ & $8.79 \pm 0.03^{\mathrm{a}}$ & $8.12 \pm 0.02^{\mathrm{bc}}$ & $8.04 \pm 0.00^{c}$ \\
\hline
\end{tabular}

Note: The values were expressed as the mean of three repetitions; the same characters (denoted above), the difference between them was not significant $(\alpha=5 \%)$. 


\section{Discussion}

Sonication can be applied during fruit juice processing in order to disrupt the pulp particles and to affect the particle size distribution (Chi and Ha, 2018). In another study, ultrasonic extraction reduced betacyanin content, TFC, and scavenging activity but increased the yield for the flesh (Nurul Shazini Ramli et al., 2014). Zafra-Rojas et al. (2013) and Zou et al. (2017) have shown that the mass transfer effects, shear, and shock waves that were generated during the acoustic cavitation process can damage fruit tissues and cell walls, resulting in the diffusion of water into fruit cells. This would ultimately result in the solubilization of more soluble solids (Zou et al., 2016). Application of ultrasound at $45^{\circ} \mathrm{C}$ for $60 \mathrm{~min}$ resulted in the highest juice yield, L-ascorbic acid content, total phenolic content, total anthocyanin content and the antioxidant capacity of the mulberry juice (Chi and Ha, 2018). The extended extraction duration would cause an exposure of abundant oxygen and thus accelerate more chances for oxidation of phenolic constituents (Naczk and Shahidi, 2004; Chirinos et al., 2007) as well as the possibility of destruction by endogenous enzymes (Kuljarachanan et al., 2009). Jahouach-Rabai et al. (2008) reported that the degradation of polyphenolic compounds was due to excessive cavitations and cell disruption of the product. Accelerated thermal treatment could improve the phenolic extraction by speeding up both diffusion coefficient and solubility of phenolic compounds in extraction solvent (Al-Farsi and Chang, 2007; Lim and Murtijaya, 2007). Thermal treatment was able to break down cellular components and release the bounded phenolics (Wang et al., 2008). However, harsh temperature likely decomposed the phenolics (Chan et al., 2009; Liyana-Pathirana and Shahidi, 2005). Some authors have postulated that the loss of TPC in treated samples at high temperature could be resulted from the degradation of phenolic compounds due to thermal effect and/or reduced free phenolic compound (Masibo and He, 2008). There was degradation in the ascorbic acid content as the temperature increased to $75^{\circ} \mathrm{C}$ due to the sensitivity of the heat of the ascorbic acid compounds (Chi and Ha, 2018).

\section{Conclusion}

Dragon fruit has greatly increased its popularity worldwide due to its attractive colours, sweet, juicy pleasant taste. It is one of the most popular commercial fruits available in Vietnam. It has potential for use as a source of functional ingredients to provide nutrients that may prevent nutrition related diseases and improve physical and mental well-being of the consumers. It is interesting to investigate some major factors possibly affecting to during acoustic extraction. Our results revealed that acoustic power, extraction duration and temperature had significant influence to the juice extraction recovery, vitamin $\mathrm{C}$, total phenolic content, total flavonoid content and organoleptic attributes of dragon fruit beverage. Acoustic treatment should be considered as an alternative method in the extraction of antioxidant-rich juices.

\section{Conflict of interest}

The authors declare that there are no conflicts of interest in the course of conducting the research. All the authors had final decision regarding the manuscript and decision to submit the findings for publication.

\section{References}

Al-Farsi, M. A. and Chang Y. L. (2007). Optimization of phenolics and dietary fibre extraction from date seeds. Food Chemistry, 108:977-985.

Barcelon, E.; Carreon, L.; Guillermo, J.; Jacob, E.; Jocson, S.; Panopio Jr. G. and Rosalinas, S. (2015). Consumer acceptability and physico-chemical content of red flesh dragon fruit spread. Australian Journal of Basic and Applied Sciences, 9:18-21.

Chan, E. W. C.; Lim, Y. Y.; Wong, S. K.; Lim, K. K.; Tan, S. P. and Lianto, F. S. (2009). Effects of different drying methods on the antioxidant properties of leaves and tea of ginger species. Food Chemistry, 113:166-172.

Chi L. Nguyen and Ha V. H. Nguyen (2018). Ultrasonic effects on the quality of mulberry juice. Beverages, 4:56.

Chirinos, R.; Rogez, H.; Campos, D.; Pedreschi, R. and Larondelle, Y. (2007). Optimization of extraction conditions of antioxidant phenolic compounds from mashua (Tropaeolum tuberosum Ruíz and Pavón) tubers. Separation and Purification Technology, 55:217-225.

Feng, H.; Yang, W. and Hielscher, T. (2008). Power ultrasound. Food Sci. Technol. Int., 14:433-436.

Fernanda Robert De Mello; Cláudia Bernardo; Carolinne Odebrecht Dias and Luana Carolina Bosmuler Züge (2014). Evaluation of the chemical characteristics and rheological behavior of pitaya (Hylocereus undatus) peel. Fruits, 69:381-390.

Herrera, M. and De Castro, M. L. (2005). Ultrasound-assisted extraction of phenolic compounds from strawberries prior to liquid chromatographic separation and photodiode array ultraviolet detection. J. Chromatogr., A 1100:1-7.

Hui Luo; Yongqiang Cai; Zhijun Peng; Tao Liu and Shengjie Yang (2014). Chemical composition and in vitro evaluation of the cytotoxic and antioxidant activities of supercritical carbon dioxide extracts of pitaya (dragon fruit) peel. Chem. Cent. J., 8:1-10.

Islam, M. Z.; Khan, M. T. H.; Hoque, M. M. and Rahman, M. M. (2012). Studies on the processing and preservation of dragon fruit (Hylocereus undatus) jelly. The Agriculturists, 10:29-35.

Jahouach-Rabai, W.; Trabelsi, M.; Van Hoed, V.; Adams, A.; Verhé, R.; De Kimpe, N. and Frikha, M. (2008). Influence of bleaching by ultrasound on fatty acids and minor compounds of olive oil. Qualitative and quantitative analysis of volatile compounds (by SPME coupled to GC/MS). Ultrason. Sonochem., 15:590-597.

K. Sudha; D. Baskaran; D. Ramasamy and M. Siddharth (2017). Evaluation of functional properties of Hylocereus undatus (white dragon fruit). International Journal of Agricultural Science and Research, 7:451-456.

Kuljarachanan, T.; Devahastin, S. and Chiewchan, N. (2009). Evolution of antioxidant compounds in lime residues during drying. Food Chemistry, 113:944-949.

Lee, W.; Yusof, S.; Hamid, N. and Baharin, B. (2006). Optimizing conditions for hot water extraction of banana juice using response surface methodology (RSM). J. Food Eng., 75:473-479.

Li, H.; Wong, C.; Cheng, K. and Chen, F. (2008). Antioxidant properties in vitro and total phenolic contents in methanol extracts from medicinal plants. Lebensmittel Wissenschaft und-Technologie, 41:385-390.

Lieu, L. N. (2010). Application of ultrasound in grape mash treatment in juice processing. Ultrason. Sonochem., 17:273-279.

Lim, Y. Y. and Murtijaya, J. (2007). Antioxidant properties of Phyllanthus amarus extracts as affected by different drying methods. LWTFood Science and Technology, 40:1664-1669. 
Liyana-Pathirana, C. and Shahidi, F. (2005). Optimization of extraction of phenolic compounds from wheat using response surface methodology. Food Chemistry, 93:47-56.

Ma, Y. Q.; Chen, J. C.; Liu, D. H. and Ye, X. Q. (2009). Simultaneous extraction of phenolic compounds of citrus peel extracts: Effect of ultrasound. Ultrason. Sonochem., 16:57-62.

Masibo, M. and He, Q. (2008). Major mango polyphenols and their potential significance to human health. Compr. Rev. Food Sci. Food. Saf., 7:309-319.

Montadher Ali Mahdi; Mustafa Taha Mohammed; Abdulkadir Mohammed Noori Jassim and Awatif I. Mohammed (2018). Phytochemical content and anti-oxidant activity of hylocereus undatus and study of toxicityand the ability of wound treatment. Plant Archives, 18:2672-2680.

Naczk, M. and Shahidi, F. (2004). Extraction and analysis of phenolics in food. Journal of Chormatography, A 1054:95-111.

Nguyen Phuoc Minh (2014). Various factors influencing to red dragon fruit (Hylocereus polyrhizus) wine fermentation. International Journal of Multidisciplinary Research and Development, 1:94-98.

Nguyen Phuoc Minh; Nguyen Phu Thuong Nhan; Diep Thi Tha; Le Kim Thuy; Lam Quoc Khai and Luong Ngoc Tu (2019). Different aspects affecting to production of dragon fruit (Hylocereus undatus) nectar. Journal of Pharmaceutical Sciences and Research, 11:1040-1043.

Nurul Shazini Ramli; Patimah Ismail and Asmah Rahmat (2014). Influence of conventional and ultrasonic-assisted extraction on phenolic contents, betacyanin contents, and antioxidant capacity of red dragon fruit (Hylocereus polyrhizus). The Scientific World Journal, 2014:964731.

Nurul, S. R. and Asmah, R. (2014). Variability in nutritional composition and phytochemical properties of red pitaya (Hylocereus polyrhizus) from Malaysia and Australia. International Food Research Journal, 21:1689-1697.

Omidizadeh, A.; Yusof, R. M.; Ismail, A.; Roohinejad, S.; Nateghi, L. and Bakar, M.Z.A. (2011). Cardioprotective compounds of red pitaya (Hylocereus polyrhizus) fruit. Journal of Food, Agriculture and Environment, 9:152-156.
Ortiz-hernández, Y. D. and Carrillo-salazar, J. A. (2012). Pitahaya (Hylocereus spp): A short review. Communicata Scientiae, 3:220-237.

Ozsoy, N.; Can, A.; Yanardag, R. and Akev, N. (2008). Antioxidant activity of Smilax excelsa L. leaf extracts. Food Chemistry, 110:571-583.

Panchal, J. B.; Gaikwad, R. S.; Dhemre, J. K. and U. D. Chavan (2018). Studies on preparation and storage of jelly from dragon fruit (Hylocereus undatus). Journal of Pharmacognosy and Phytochemistry, 7:2648-2655.

Rodrigues, S. and Pinto, G. A. (2007). Ultrasound extraction of phenolic compounds from coconut (Cocos nucifera) shell powder. J. Food Eng., 80:869-872.

Sushmitha, H. S. and Balasubramanian Sathyamurthy (2018). In silico drug designing studies on dengue virus envelope protein. World Journal of Pharmaceutical Sciences, 6:138-143.

Valero, M.; Recrosio, N.; Saura, D.; Muñoz, N.; Martí, N. and Lizama, V. (2007). Effects of ultrasonic treatments in orange juice processing. J. Food Eng., 80:509-516.

Vilkhu, K.; Mawson, R.; Simons, L. and Bates, D. (2008). Applications and opportunities for ultrasound assisted extraction in the food industry: A review. Innov. Food Sci. Emerg. Technol., 9:161-169.

Wang, J.; Sun, B.; Cao, Y.; Tian, Y. and Li, X. (2008). Optimisation of ultrasound-assisted extraction of phenolic compounds from wheat bran. Food Chemistry, 106:804-810.

Yogita Temak; Pravin Cholke; Akshay Mule; Akahay Shingade, Sudam Narote; Aditee Kagde; Rutuja Lagad and Vaishnavi Sake (2018). In vivo and in vitro evaluation of antimicrobial activity of peel extracts of red dragon fruit (Hylocereus polyrhizus). International Journal of Research in Pharmacy and Pharmaceutical Sciences, 3:24-26.

Zafra-Rojas, Q.Y.; Cruz-Cansino, N.; Ramírez-Moreno, E.; Delgado-Olivares, L.; Villanueva-Sánchez, J. and Alanís-García, E. (2013). Effects of ultrasound treatment in purple cactus pear (Opuntia ficus-indica) juice. Ultrason. Sonochem., 20:1283-1288.

Zou, Y. and Hou, X. (2017). Sonication enhances quality and antioxidant activity of blueberry juice. Food Sci. Technol., 37:599-603.

Zou, Y. and Jiang, A. (2016). Effect of ultrasound treatment on quality and microbial load of carrot juice. Food Sci. Technol., 36:111-115.

Citation: Minh Phuoc Nguyen (2020). Processing of dragon fruit beverage by acoustic treatment. Ann. Phytomed., 9(1):129132. http://dx.doi.org/10.21276/ap.2020.9.1.16 